\title{
Defensive enrolment in mantis shrimp larvae (Malacostraca: Stomatopoda)
}

\author{
Carolin Haug ${ }^{1,2}$, Joachim T. Haug ${ }^{1}$ \\ ${ }^{1}$ LMU Munich, Department of Biology II and GeoBio-Center, Großhaderner Str. 2, 82152 Planegg-Martinsried, \\ Germany \\ ${ }^{2}$ carolin.haug@palaeo-evo-devo.info
}

Key words: defensive behaviour, functional morphology, marine larvae, museum material

\begin{abstract}
We describe a possible new defensive behaviour of larval stages of mantis shrimps (Stomatopoda). Mantis shrimp larvae are rarely observed in nature, thus the study is based on postures of museum material and functional morphological aspects. Specimens described here are tightly enrolled, their pleon is bent forward, and the telson is locked into the frontal margin of the shield. This margin has two lobes into which the two posterolateral spines of the telson fit. The shield shows further adaptions to enrolment; $e . g$., the ventral gape of the shield perfectly matches the width of the pleon and leaves no major gaps when the pleon is bent forward. Based on these observations, we briefly discuss the possibilities to infer behavioural aspects from functional morphological aspects. Enrolment in modern day organisms is primarily known from terrestrial arthropods, e.g., pill bugs and pill millipedes, but in the Palaeozoic it was mainly performed by marine organisms such as trilobites, agnostines and their relatives. Stomatopod larvae that appear to be able to perform enrolling in a marine environment are therefore a potential functional equivalent for better understanding the functional aspects of enrolment in extinct marine arthropods.
\end{abstract}

\section{Contents}

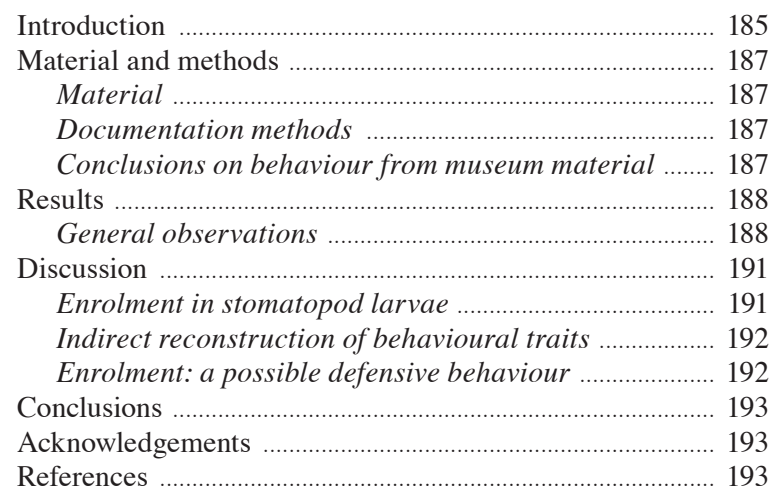

\section{Introduction}

Arthropods display a large variety of defensive strategies against predators and other threats. For example, numerous groups developed escape reactions. Wellknown examples of groups with such a reaction are caridoid eucrustaceans, leaf hoppers, and orthopteran insects (e.g., Carew, 2000; Burrows, 2007; Burrows and Picker, 2010). Other defensive strategies involve the development of defensive structures: the body of arthropods can be armed with strong spines, serrations or heavily sclerotised dorsal sclerites, or the entire body can be enclosed in large shields. In some arthropods, a combination of several of these defensive aspects can be found. For example, many orthopterans arm their jumping legs, which they use for their escape reaction, with stout spines (e.g., Field and Glasgow, 2001). Daphniid crustaceans, with their bivalved shield enclosing their entire body, additionally employ strong spines for protection (e.g., Swaffar and O'Brien, 1996).

Another such combined defensive strategy is enrolment, wherein both structural and behavioural aspects act in synergy. The entire body of the arthropod is strongly curved ventrally, forming more or less a ball, so that the anterior and the posterior end lie adjacent to each other. In such a position, the (often strongly sclerotised) dorsal surfaces of the segments face outside, while the more membranous ventral side including the appendages is protected in the inside of the ball. In the extant fauna, such a defensive behaviour is displayed, for example, by species of the myriapod groups Sphaerotheriida (e.g., Golovatch, 2003) and Glomerida (pill millipedes; Fig. 1A-B), and by pill bugs, i.e., species of the crustacean isopod group Armadillidium (Fig. 1C-D).

Trilobites are a diverse group of exclusively fossil euarthropods, of which most representatives also displayed enrolment. In some species, specialised structures (frequently referred to as 'coaptative structures') were developed on the ventral side of the head and tail shield (pygidium), which allowed a tight interlocking of these two structures (Feist et al., 2010; Fig. 1E-F). This would additionally secure the enrolled position if a predator would try to 'open' the defending animal. 


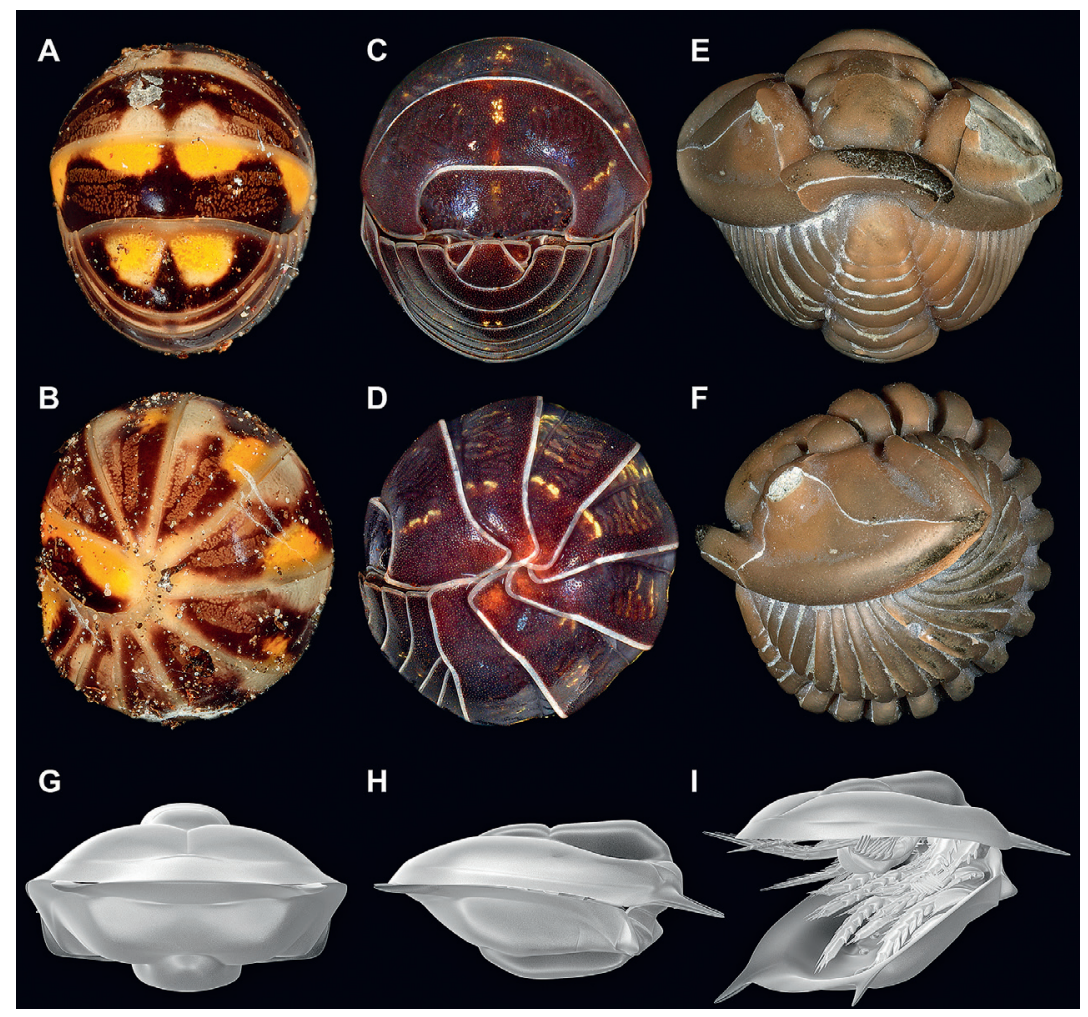

Fig. 1. Commonly known enrolling arthropods. A-B. Pill millipede, Glomeris sp. (Diplopoda). A. Frontal view. B. Lateral view. C-D. Pill bug (woodlouse), Armadillidium sp. (Isopoda). C. Frontal view. D. Lateral view. E-F. Flexicalymene sp. (Trilobita). E. Frontal view. F. Lateral view. G-I. Agnostus pisiformis (Wahlenberg, 1818) (Agnostina). G. Frontal view. H. Lateral view. I. Presumed life position. A-F are composite images under cross-polarised light; G-I are computer-generated 3D models based on Müller and Walossek (1987).

Other exclusively fossil euarthropods that were highly specialised for enrolment include the agnostines (often considered to be trilobites, but see, e.g., Haug et al., 2010; Stein and Selden, 2012) and certain nektaspidids, a group of superficially trilobite-like euarthropods (e.g., Budd, 1999). Among agnostines, some spe- cies such as Agnostus pisiformis (Wahlenberg, 1818) (Fig. 1G-I) even appear to have spent their entire life fully or partly enrolled, as they seem to have been unable to stretch their bodies straight (Müller and Walossek, 1987; Bruton and Nakrem, 2005).

Even among fossil chelicerates, some representa-

Table 1. Sampling information of the mantis shrimp larvae investigated in this study.

\begin{tabular}{|c|c|c|c|c|c|c|}
\hline Repository number & Station & Latitude & Longitude & Date & Locality & Depth in $\mathrm{m}$ \\
\hline ZMUC-CRU-20243 & $1192-7$ & $17^{\circ} 43.4^{\prime} \mathrm{N}$ & $64^{\circ} 54.3^{\prime} \mathrm{W}$ & 15 Dec. 1921 & W of St. Croix, Virgin Islands & 410 \\
\hline ZMUC-CRU-20244 & $3809-3$ & $6^{\circ} 22^{\prime} \mathrm{S}$ & $105^{\circ} 12^{\prime} \mathrm{E}$ & 4 Sep. 1929 & W of Java, Indonesia & 1050 \\
\hline ZMUC-CRU-20245 & $3949-2$ & $11^{\circ} 33^{\prime} \mathrm{S}$ & $41^{\circ} 44^{\prime} \mathrm{E}$ & 6 Jan. 1930 & N Mozambique & 1890 \\
\hline ZMUC-CRU-20246 & $3958-1$ & $23^{\circ} 11^{\prime} \mathrm{S}$ & $42^{\circ} 54^{\prime} \mathrm{E}$ & 11 Jan. 1930 & W of Tulear, Madagascar & 3100 \\
\hline ZMUC-CRU-20247 & $3958-1$ & $23^{\circ} 11^{\prime} \mathrm{S}$ & $42^{\circ} 54^{\prime} \mathrm{E}$ & 11 Jan. 1930 & W of Tulear, Madagascar & 3100 \\
\hline ZMUC-CRU-20248 & $3958-2$ & $23^{\circ} 11^{\prime} \mathrm{S}$ & $42^{\circ} 54^{\prime} \mathrm{E}$ & 11 Jan. 1930 & W of Tulear, Madagascar & 3100 \\
\hline ZMUC-CRU-20249 & $3958-3$ & $23^{\circ} 11^{\prime} \mathrm{S}$ & $42^{\circ} 54^{\prime} \mathrm{E}$ & 11 Jan. 1930 & W of Tulear, Madagascar & 3100 \\
\hline ZMUC-CRU-20250 & $3958-3$ & $23^{\circ} 11^{\prime} \mathrm{S}$ & $42^{\circ} 54^{\prime} \mathrm{E}$ & 11 Jan. 1930 & W of Tulear, Madagascar & 3100 \\
\hline ZMUC-CRU-20251 & $3958-3$ & $23^{\circ} 11^{\prime} \mathrm{S}$ & $42^{\circ} 54^{\prime} \mathrm{E}$ & 11 Jan. 1930 & W of Tulear, Madagascar & 3100 \\
\hline ZMUC-CRU-20252 & $3958-3$ & $23^{\circ} 11^{\prime} \mathrm{S}$ & $42^{\circ} 54^{\prime} \mathrm{E}$ & 11 Jan. 1930 & W of Tulear, Madagascar & 3100 \\
\hline ZMUC-CRU-20253 & $3958-3$ & $23^{\circ} 11^{\prime} \mathrm{S}$ & $42^{\circ} 54^{\prime} \mathrm{E}$ & 11 Jan. 1930 & W of Tulear, Madagascar & 3100 \\
\hline ZMUC-CRU-20254 & $3958-3$ & $23^{\circ} 11^{\prime} \mathrm{S}$ & $42^{\circ} 54^{\prime} \mathrm{E}$ & 11 Jan. 1930 & W of Tulear, Madagascar & 3100 \\
\hline ZMUC-CRU-20255 & $3958-3$ & $23^{\circ} 11^{\prime} \mathrm{S}$ & $42^{\circ} 54^{\prime} \mathrm{E}$ & 11 Jan. 1930 & W of Tulear, Madagascar & 3100 \\
\hline ZMUC-CRU-20256 & $3958-3$ & $23^{\circ} 11^{\prime} \mathrm{S}$ & $42^{\circ} 54^{\prime} \mathrm{E}$ & 11 Jan. 1930 & W of Tulear, Madagascar & 3100 \\
\hline ZMUC-CRU-20257 & $3958-3$ & $23^{\circ} 11^{\prime} \mathrm{S}$ & $42^{\circ} 54^{\prime} \mathrm{E}$ & 11 Jan. 1930 & W of Tulear, Madagascar & 3100 \\
\hline ZMUC-CRU-20258 & $3958-3$ & $23^{\circ} 11^{\prime} \mathrm{S}$ & $42^{\circ} 54^{\prime} \mathrm{E}$ & 11 Jan. 1930 & W of Tulear, Madagascar & 3100 \\
\hline
\end{tabular}


tives appear to have been able to perform enrolment. The 300 million year old xiphosuran Alanops magnificus possessed highly domed prosomal and opisthosomal shields, providing space for the sturdy appendages (Racheboeuf et al., 2002). Other xiphosuran fossils that have been interpreted as representing enrolled specimens (Fisher, 1977; Anderson, 1994) have been questioned; for example, enrolledappearing representatives of Euproops seem more likely to represent preservational positions of exuviae (Haug et al., 2012a).

Given the broad taxonomic distribution of defensive enrolment, one could come to the conclusion that enrolling was a successful and widely distributed strategy for aquatic arthropods in the past, but today is only found in few specialised terrestrial forms. Here we report enrolling in extant marine arthropods, namely larval stages of mantis shrimps, based on museum material. We describe variations of this specific strategy and briefly discuss how museum material can be used to infer behavioural aspects of animals that cannot easily be observed directly.

\section{Material and methods}

\section{Material}

All investigated larval mantis shrimp (stomatopod) specimens come from the collection of the Zoological Museum of the University of Copenhagen (ZMUC). Specimens were collected during the famous Dana expeditions (1921-22 and 1928-30; Schmidt, 1926, 1931; Broch, 1936), and have come exclusively from plankton samples (for details on the sampling sites, see Table 1). All specimens are stored in $70 \%$ ethanol, but based on the appearance of the specimens, early storage, or at least fixation, seems to have been in formaldehyde.

\section{Documentation methods}

Specimens were documented directly within their storage liquid, i.e., 70\% ethanol. Specimens show a certain flexibility. For ventral and dorsal documentation, some specimens were carefully outstretched and fixed with a cover slip. For large specimens, posterior and anterior ends were fixed with a separate cover slip each. In other orientations, specimens were either leaned against glass or metal objects, or placed into depressions. Specimens in unusual positions were not altered, but kept in this specific position.

Specimens were photographed with a Canon Rebel T3i digital camera with a MP-E $65 \mathrm{~mm}$ macro lens. Light was provided by a Canon Macro Twin Flash MT 24 or a Meike FC 100 LED ring light. Light sources were equipped with polarisation filters. A cross-polarised filter was placed in front of the lens. Cross-polarised light reduces reflections and enhances the colour contrast (e.g., Haug et al., 2011 and references therein). To overcome limited depth of field in higher magnifications, stacks of images were recorded, each single frame in a different focal plane. Stacks were fused using CombineZM/ZP or Image Analyzer. To overcome limitations of field of view in higher magnifications, several adjacent image details were recorded, each one with a stack. Fused images for each image detail were stitched together using Microsoft Image Composite Editor or the photomerge function of Adobe Photoshop CS3 (for details see Haug et al., 2009, 2011). Further processing such as optimisations of histograms, saturation, sharpness (mask unsharp filter) and manual cleaning of the background was performed in Adobe Photoshop CS3. Some specimens were additionally documented as stereo images. For this purpose, specimens were documented in different viewing angles (e.g., Haug et al., 2011). Red-cyan anaglyphs based on stereo pairs were produced in Adobe Photoshop CS3 or CS6.

\section{Conclusions on behaviour from museum material}

Direct observation of most larval stages of stomatopods is generally not possible in a laboratory setting, as it is very difficult to rear them. Nonetheless, fixed material from plankton samples of extant stomatopod larvae can provide valuable insights to their behaviour in a comparable way to how fossils allow the reconstruction of behavioural aspects of extinct organisms (e.g., Haug et al., 2012b, c, 2013). These indications comprise two aspects: 1) Functional morphology, i.e., addressing questions such as which movements does the morphology allow the organism to perform or which functions could certain structures fulfil. 2) Positions in which specimens are preserved (see also Mayer et al., 2013); here a careful consideration is necessary to differentiate possible true lifetime positions from 'dying poses', post-mortem poses, or simply storage deformations such as those resulting from a large specimen being stored in a small jar, or when numerous specimens have been stuffed together into a single jar. 


\section{Results}

The following discussion is restricted to addressing certain morphotypes of mantis shrimp larvae, not species. Though currently almost 500 species of extant mantis shrimps are described, we know the larval sequences of only a handful of them (e.g., Manning and Provenzano, 1963; Provenzano and Manning, 1978; Greenwood and Williams, 1984; Morgan and Goy, 1987; Diaz, 1998; Ahyong et al., accepted). Although some work has been done on larval disparity of mantis shrimps (although the most important papers are mostly many decades old and did not utilize up-todate imaging methods, e.g., Giesbrecht, 1910; Shanbhogue, 1975) the exact assignment of larvae to specific species is still a very challenging task. Recent successes in culturing and DNA barcoding are promising (Tang et al., 2010) and might allow future improvements in this respect. For the here presented observations, the ascription to specific species is not seen as an important aspect; therefore the restriction to morphotypes is, in our view, not necessarily problematic.

\section{General observations}

Numerous specimens in the extensive stomatopod larvae collection of the ZMUC show an unusual or at least unexpected position: their pleon is flexed far ventrally and anteriorly so that the telson comes close to the anterior part of the head. All specimens showing this posture are of an erichthus type of larva with a bulging shield. The ventral gape of the shield corresponds exactly to the width of the pleon and the telson.

Non-erichthus-type larvae also show a certain flexure of the pleon, but usually not that far anteriorly. A correlation between the ventral gape (in cases of alima-type larvae the shield is so flat that 'gape' is an inappropriate term) and the width of the often very narrow pleon and the often quite broad telson was not observed.

Specimen 1: In specimen ZMUC-CRU-20248 the pleon is flexed far anteriorly, and the telson comes to lie inside the shield, close to its anterior rim (Fig. 2). The pleon width fits perfectly into the ventral gape of the shield as does the telson. All appendages and the compound eyes are 'inside', protected by shield, pleon and telson. The entire specimen appears like a compact ball, armed with spines. This posture is referred to as fully enrolled; in the following listing of specimens, this morphology is referred to as morphotype 1 .

The shield possesses two lobe-like elevations on its anterior ventral rim, slightly laterally positioned. Under these lobes, the spines of the postero-lateral corners of the telson come to rest. These lobes appear to partly 'lock' the telson in this position.

Specimen 2: This specimen (ZMUC-CRU-20246) strongly resembles specimen 1 (ZMUC-CRU-20248) and is thus also considered morphotype 1 , but is slightly larger, possibly representing a later instar of the same species, or corresponding to a later instar of another species. In this specimen a part of the large shield is broken off, allowing a view on arrangement of the appendages in the enrolled posture (Fig. 3A-C). ZMUC-CRU-20246 clearly demonstrates that none of the joints between the pleomeres is overflexed or overstretched in this position and that the appendages neatly fit into the space between the shield, pleon and telson.

Specimen 3: Specimen ZMUC-CRU-20244 appears to be of the same morphotype as the preceding two (morphotype 1), and about the same size class as specimen 1 (ZMUC-CRU-20248). It is only partly enrolled, allowing a partial view from the anterior into the enrolled arrangement of the appendages (Fig. 3DF). It becomes obvious that in this slightly opened posture the eyes are among the first structures to become exposed.

Specimen 4: Specimen ZMUC-CRU-20243 resembles the preceding specimens in general morphology. However, the specimen was only slightly curled and could be easily outstretched (Fig. 4). This specimen shows that the morphology of this morphotype also allows a fully outstretched posture.

Specimen 5: Specimen ZMUC-CRU-20245 resembles ZMUC-CRU-20244 in the partly opened posture, but apparently represents another morphotype (morphotype 2) with longer shield spines and a shorter telson (Fig. 5A-D). Also the general shield morphology appears wider. The correlation between ventral gape and width of pleon and telson appears less strict in this morphotype, as some gaps remain when the pleon is flexed forward. Although the pleon is fully enrolled, the telson does not reach the anterior rim of the shield due to the shorter telson. Therefore, some structures remain unconcealed. Compound eyes, antennulae and antennae remain exposed, as do the distal three articles of the large raptorial appendages. The shield gape widens slightly in the middle region of the telson, apparently allowing the raptorial appendages also to be sticking out laterally from the telson.

Specimen 6: Specimen ZMUC-CRU-20247 appears to be of the same morphotype as specimen 

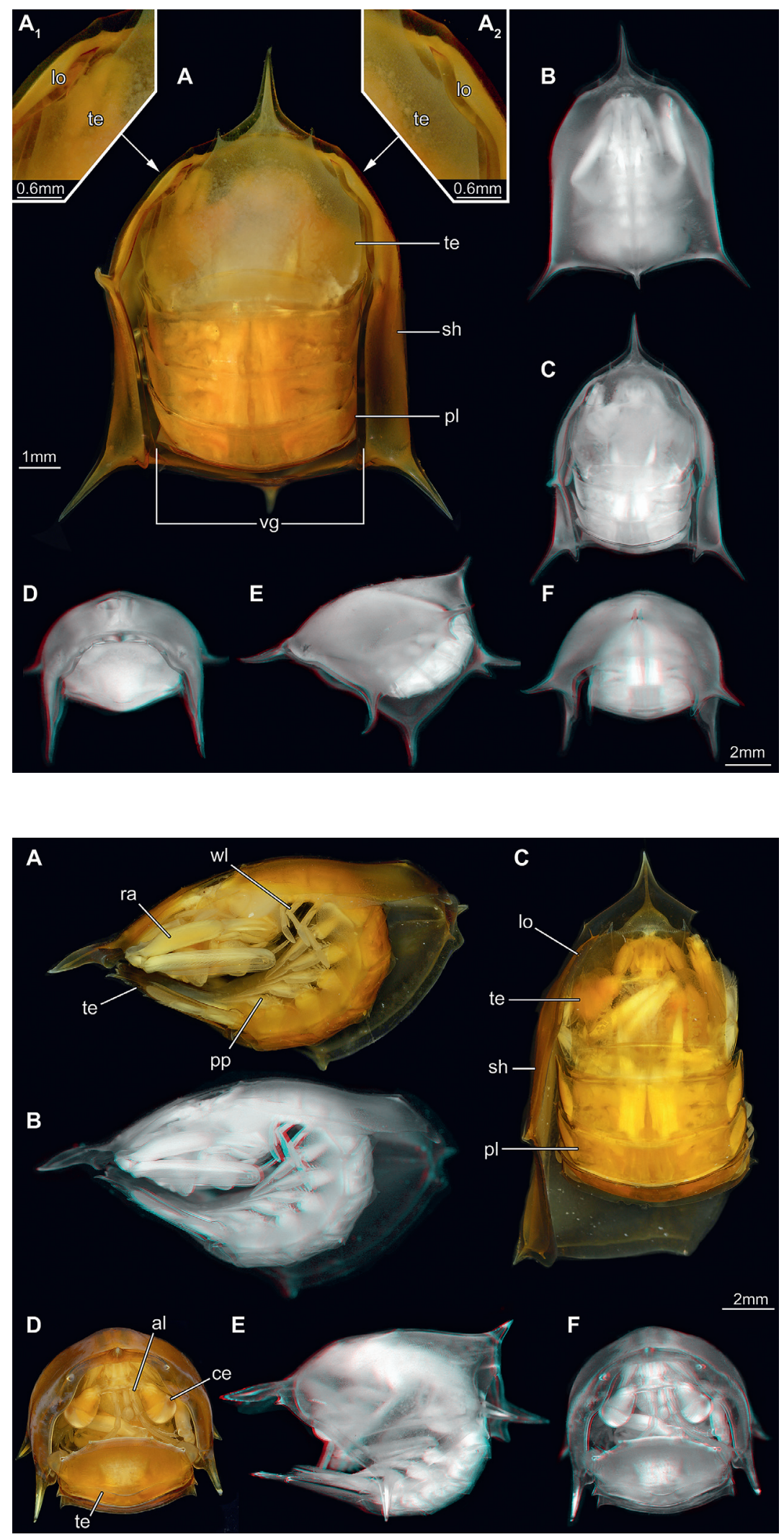

Fig. 2. Erichthus-type mantis shrimp larva of morphotype 1, fully enrolled, ZMUC-CRU-20248. A. Quasi-ventral view; note the ventral gape of the shield. $A_{1}, A_{2}$. Close-ups on the the region of the shield where the telson spines are locked below lobes of the shield. B-F. Red-cyan stereo-anaglyph images (please use redcyan glasses to view, red left, cyan right); note that the enrolled specimen is a functional ball armed with spines. B. Dorsal view. C. Quasi-ventral view. D. Frontal view. E. Lateral view. F. Posterior view. Abbreviations: lo $=$ lobe of shield; $\mathrm{pl}=$ pleon; $\mathrm{sh}=$ shield; te = telson; $\mathrm{vg}=$ ventral gape.
Fig. 3. Erichthus-type mantis shrimp larvae of morphotype 1. A-C. Fully enrolled specimen ZMUC-CRU-20246, parts of the shield broken off, facilitating a view onto the position of the appendages in enrolled posture. A-B. Lateral view. C. Quasi-ventral view. D-F. Partly enrolled specimen ZMUC-CRU-20244. D, F. Frontal view, E. Lateral view. B, E and $\mathrm{F}$ are red-cyan stereo-anaglyph images. Abbreviations: al $=$ antennula; $c e=$ compound eye; lo = lobe of shield; $\mathrm{pl}=$ pleon; $\mathrm{pp}=$ pleopod; $\mathrm{ra}=$ raptorial appendage; sh $=$ shield; te = telson; $w \mathrm{l}=$ walking leg. 

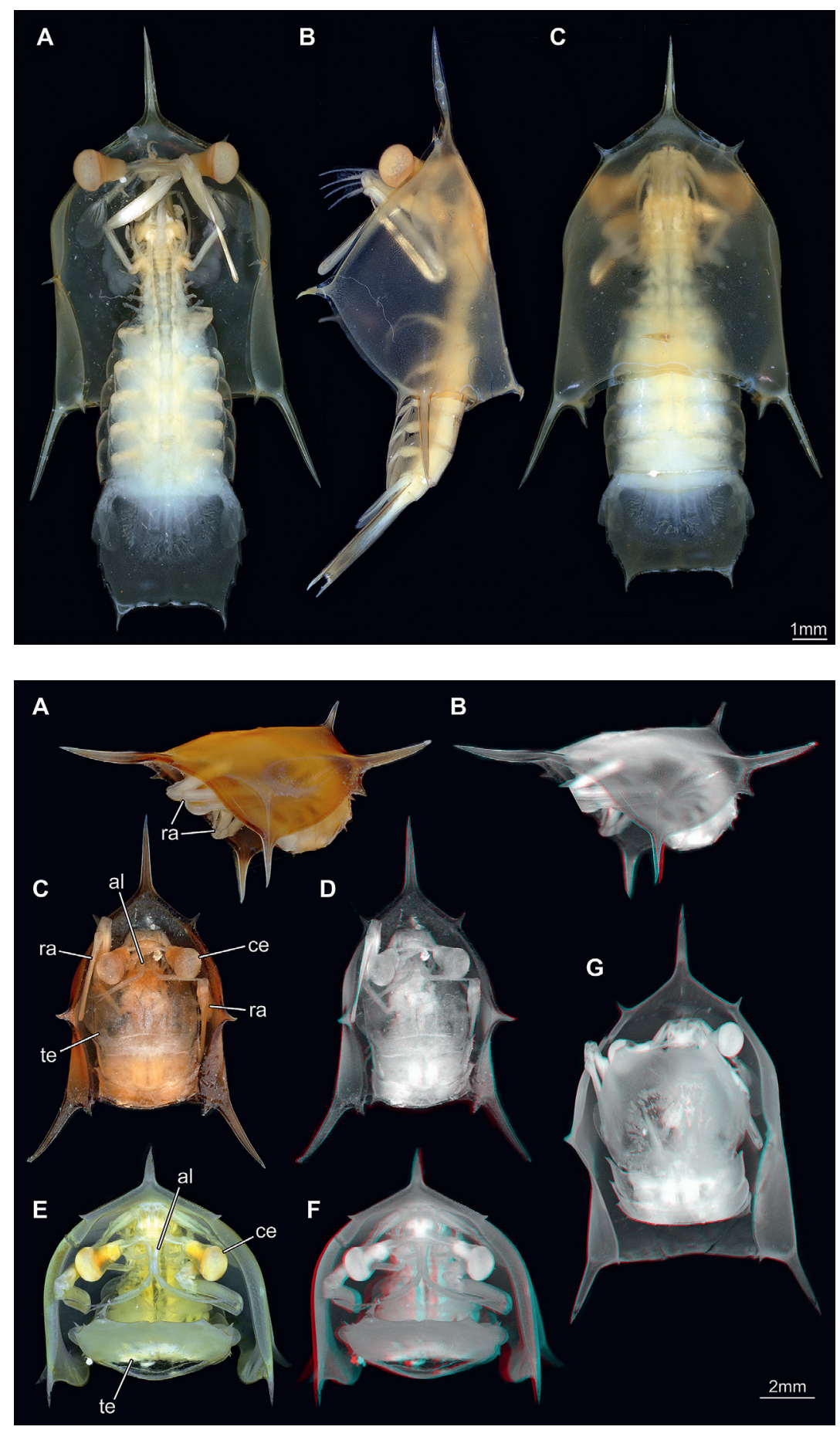

Fig. 4. Erichthus-type mantis shrimp larva of morphotype 1, fully outstretched, ZMUC-CRU-20243. A. Ventral view. B. Lateral view. C. Dorsal view.
Fig. 5. Erichthus-type mantis shrimp larvae of morphotype 2. A-D. Fully enrolled specimen, ZMUC-CRU-20245. A-B. Lateral view. C-D. Quasi-ventral view. E-G. Partly enrolled specimen, ZMUC-CRU-20247. E-F. Frontal view. G. Ventral view. B, D, F-G are red-cyan stereo-anaglyph images. Abbreviations: $\mathrm{al}=$ antennula $; \mathrm{ce}=$ compound eye; $\mathrm{ra}=$ raptorial appendage; te $=$ telson .
ZMUC-CRU-20245, yet of a slightly larger size class (Fig. 5E-G). The specimen is not as tightly closed as the previous specimen, and as in the latter, the eyes and anterior appendages are sticking out.

Specimens 7-16: Enrolled specimens are quite com- mon within the samples. As an example, all enrolled specimens from a single sample are shown in Fig. 6 (ZMUC-CRU-20249 until 20258). The sample contains 99 specimens of stomatopod larvae of varying sizes, half of them being erichthus-type larvae (which 


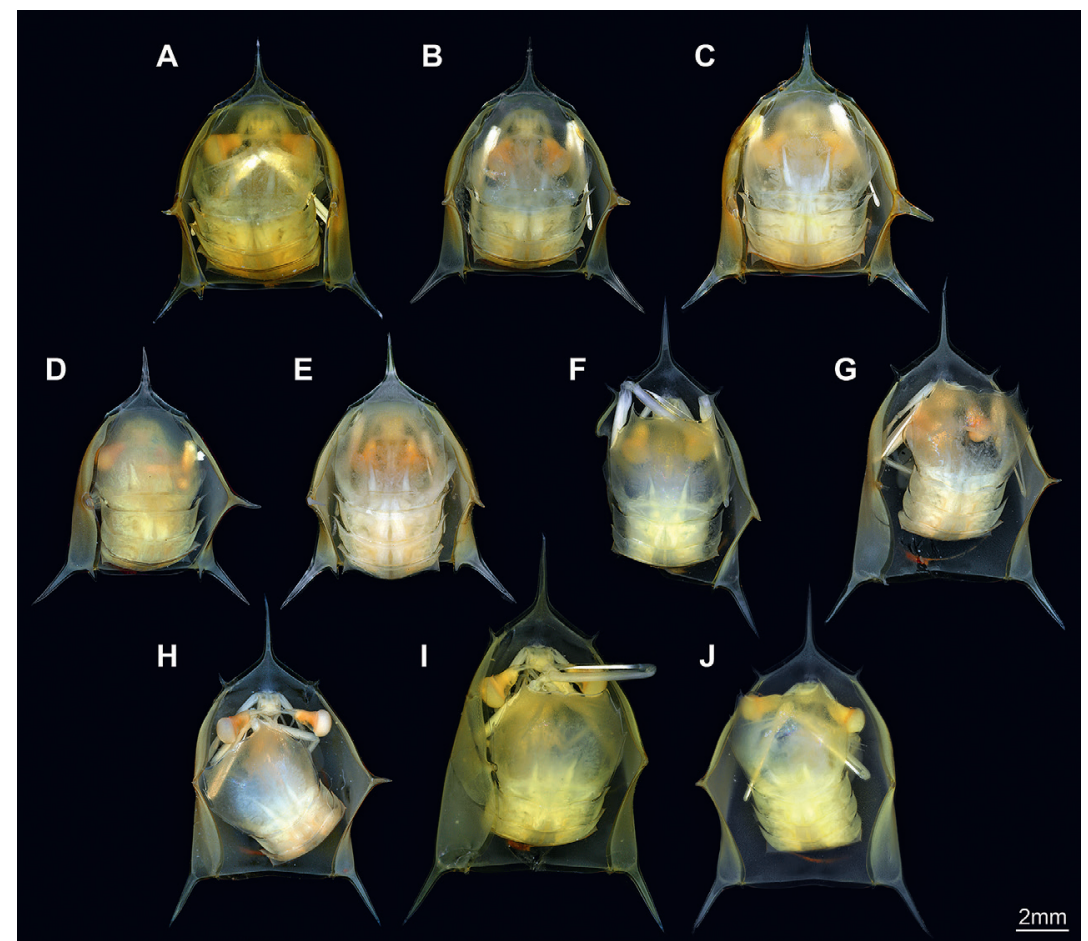

Fig. 6. Erichthus-type mantis shrimp larvae of morphotype 1 and 2 . Ten specimens from a single sample in partly or fully enrolled posture, ZMUC-CRU -20249 until 20258. is an unusually high value; normally, alima or smaller larvae dominate the samples). In total, ten of the erichthus-type larvae of this sample show a fully or partially enrolled posture. Although not a statistical measure, this number can give an indication that the partly or fully enrolled posture may be quite widespread.

\section{Discussion}

\section{Enrolment in stomatopod larvae}

As the specimens described here demonstrate, erichthus-type mantis shrimp larvae can flex their pleon far ventrally and anteriorly, so that the telson comes to be close to the anterior part of the head. The question then arises as to whether this posture represents a natural position, or simply a dying pose or a storage deformation? In fact, other types of stomatopod larvae also show a flexure of the pleon, so the position alone does not seem to be very telling. Yet, as discussed previously, posture is just one aspect that should be considered here, with another important aspect being functional morphology.

Considering the functional morphology, first of morphotype 1, the following points are important:
1) Unlike in other stomatopod larval forms, the shield is not very widely opened ventrally, but the left and right part come clearly closer together towards the ventral side of the body. This leads to a specific ventral gape of the shield.

2) The width of the pleon is closely correlated to the ventral gape, so that it 'just fits in', and that over the entire length of the pleon. In other larval forms, such as the alima, the pleon is very narrow and elongate.

3) The width of the telson is also closely correlated to the width of the ventral gape; it therefore has the same width as the pleon. In other larvae, the telson is slightly to drastically wider than the pleon.

4) The telson can interlock with the two lobes of the shield, leading to a very tight closure.

5) The segments of the pleon in the enrolled positions do not appear overstretched or overflexed.

6) All appendages fit well into the chamber formed by shield, pleon and telson.

From a functional morphological point, we can state that the erichtus-type larvae of morphotype 1 are in principle able to perform enrolling and appear to possess specialised coaptative structures to secure such a position. The body of these larvae appears to be 
specifically adapted to perform such a movement. This observation, together with the fact that specimens in this posture are frequently encountered within the studied material, give an indication that this kind of enrolling represents a true aspect of the behavioural reportoire of the erichtus larvae of morphotype 1.

The case seems less strict for morphotype 2. Here the enrolling posture seems less fixed, and the pleon seems to have a certain flexibility in its position. Moreover, the correlation of width of the ventral gape and width of the pleon appears to be less strict. And finally, with the shorter telson and the lack of coaptative structures, there are clearly less specific adaptations for enrolling than in morphotype 1 . Yet, as the case for morphotype 1 is based on numerous adaptations, there should be enrolment morphologies present with only part of these adaptations. Thus, we believe it is plausible that morphotype 2 also performed enrolling, but represents a form that is less specialised for this behaviour than morphotype 1 .

\section{Indirect reconstruction of behavioural traits}

The argumentation presented here is best comparable to the reconstruction of behavioural or autecological aspects of extinct organisms. In extinct organisms, a direct observation of their behaviour is impossible, and only functional morphological aspects as well as positional information of numerous specimens can be used to infer possible aspects of the behavioural repertoire of the organisms (e.g., Wedmann et al., 2007; Benton, 2010; Poinar, 2010; Haug et al., 2012b, c, 2013 and references therein).

For extant organisms, a direct observation of behavioural aspects is desirable. Yet, as in the case of stomatopod larvae, direct observation of many organisms is rather challenging. In general, the behaviour of stomatopod larvae is still a largely unstudied field. Therefore, an indirect consideration, as presented here, represents an important alternative to direct observation in the field. Especially functional morphological considerations can form an important basis for understanding how unobservable processes might take place. As with other scientific hypotheses in biological sciences, the case herein presented represents a plausible scenario that can only be corroborated by direct observation in the field (first hints noted by M. Erdmann, pers. com.).

Such an indirect reconstruction of behavioural aspects is especially valuable in groups of which we know only little about their actual behaviour. Stomato- pod larvae are diverse, in fact comprising numerous morphotypes that must occupy also numerous different ecological niches and possess quite differentiated behaviour. The observations presented here provide merely a first glimpse into this diversity, but are therefore seen as especially important. This case furthermore stresses the potential of the use of museum collections for biological aspects beyond taxonomy and even biodiversity.

\section{Enrolment: a possible defensive behaviour}

In other arthropods that can perform enrolling, this strategy is employed as a defensive behaviour. This seems to be also a plausible explanation for the observed behaviour in stomatopod larvae. The shield of the erichthus-type larvae described here is armed with numerous strong spines. Moreover, the telson edge is equipped with spines and denticles, and the tergopleurae of the pleomeres are postero-distally drawn out into spine-like extensions. When enrolled, the entire animal appears like a spiky ball. Thus, the interpretation of the enrolment as a defensive posture is highly plausible. Especially for morphotype 1, in which the enrolling is additionally secured by coaptative structures, enrolling is best understood as a defensive reaction to a direct threat.

The type of enrolling seen in morphotype 1 is similar to that of many trilobites and pill bugs: the head shield forms a kind of 'lid' (not to be confused with the basket and lid enrolment of Bergström, 1973), with structures 'gripping around' the rim of the posterior end, in this case the telson. This posture is termed 'sphaeroidal enrolment' in trilobite terminology. Pill millipedes actually enrol in a different way; in those animals, the head is folded inside, more comparable to the 'double enrolment' in trilobite terminology.

For morphotype 2, several different interpretations are possible, although they must remain more speculative. The spines on the shield, besides being defensive structures, additionally should enhance buoyancy (e.g., Gurney, 1942). Thus, when enrolled the animal would not immediately sink, but float for some time. As the eyes, antennulae, and the large first pair of raptorial appendages can stick out even if enrolled in morphotype 2, we can speculate that this posture was not only used under direct threat. The animal could float in this posture and still wait for possible prey passing by. As mantis shrimp larvae are ambush predators, this posture should not affect their general predation strategies, but would provide immediate protection if being 
attacked by other predators. Additionally, the posture would alter the silhouette of the mantis shrimp larvae; specifically, it would make it smaller. Examples of arthropods feeding in an enrolled position are agnostinids, at least some representatives, such as Agnostus pisiformis. Yet, A. pisiformis was not a predator but swept in food particles (Müller and Walossek, 1987; Bruton and Nakrem, 2005).

Based on taxonomic examples of arthropods which can perform enrolment, it appears to be a strategy that was extremely successful in the past, especially in the Palaeozoic, in marine arthropods. The fact that dominant groups such as trilobites heavily relied on this strategy demonstrates the value of it. Enrolment was also not restricted to benthic animals, but, as in the case of agnostinids, was also performed by pelagic or better planktic forms. The list of modern animals that perform enrolment should now include stomatopod larvae. Particularly interesting is that these organisms are more similar in the use of enrolment to some of the Palaeozoic forms than other modern forms. While pill bugs and pill millipedes are exclusively terrestrial (and therefore more comparable to benthic organisms), stomatopod larvae as marine planktonic animals occupy a completely different ecological niche. Stomatopod larvae thus provide an interesting functional model for understanding enrolment in fossil organisms. In most cases, we only know the dorsal parts of fossil arthropods that performed enrolling, though a notable exception is A. pisiformis. Interestingly, the arrangement of the appendages in the fully enrolled position in A. pisiformis and in stomatopod larvae of morphotype 1 appears very similar. This arrangement might therefore well be a general solution for the space restriction inside the enrolled body and can serve for reconstructing appendage 'storing' in other organisms such as trilobites.

\section{Conclusions}

A general conclusion of our study is that our knowledge of stomatopod larvae seems still very limited. Larval biology of mantis shrimps would thus appear to be a promising field of research. Summarising the discussion, our observations indicate the following:

- Enrolment is very likely performed actively by stomatopod larvae.

- This behaviour is most likely employed as a defensive one under a direct threat, but other strategies could be coupled to it.
- Enrolment was not only successful in the sea in the Paleozoic and is today only found in few terrestrial groups, but is still also found in modern marine animals.

- Museum specimens can be used to infer behavioural and autecological aspects for animals which cannot be directly observed.

\section{Acknowledgements}

This study would not have been possible without the help of numerous persons and institutions, who are all heartily thanked in the following. Jørgen Olesen, Tom Schiøtte, Danny Eibye-Jacobsen, and Jens T. Høeg, all from the Zoological Museum of Copenhagen, helped with the work in the collections, equipment and curating the material. Gideon T. Haug, Neuried, assisted with the photography and found numerous of the interesting specimens. The manuscript has benefitted from comments of Mark Erdmann, Conservation International Bali for which we are very thankful. Both authors were supported by their former host, Steffen Harzsch, University of Greifswald, and are now supported by J. Matthias Starck, LMU Munich. The research visit of $\mathrm{CH}$ has been made possible by a grant from the European Commission's (FP 6) Integrated Infrastructure Initiative programme SYNTHESYS (DK-TAF-2591). This study is part of the research project 'Palaeo-Evo-Devo of Malacostraca' kindly funded by the German Research Foundation (DFG) under HA 6300/3-1. This study was also supported by people providing free or extremely low cost software, such as CombineZM/ZP, Image Analyzer, Microsoft Image Composite Editor, and OpenOffice.

\section{References}

Ahyong ST, Haug JT, Haug C. accepted. Order Stomatopoda. In: Martin JW, Olesen J, Høeg JT., eds, Atlas of Crustacean Larvae. Baltimore, Maryland: The Johns Hopkins University Press.

Anderson LI. 1994. Xiphosurans from the Westphalian D of the Radstock Basin, Somerset Coalfield, the South Wales Coalfield and Mazon Creek, Illinois. Proceedings of the Geological Association 105: 265-275.

Benton MJ. 2010. Studying function and behavior in the fossil record. PLoS Biology 8: e1000321. doi:10.1371/journal. pbio. 1000321

Bergström J. 1973. Organization, life, and systematics of trilobites. Fossils and Strata 2: 1-69.

Broch H. 1936. Johannes Schmidts „Dana“-Expedition um die Welt, 1928-30, und ihre Bedeutung. Die Naturwissenschaften 24: 342-345.

Bruton DL, Nakrem HA. 2005. Enrolment in a Middle Ordovician agnostoid trilobite. Acta Palaeontologica Polonica 50: 441-448.

Budd GE. 1999. A nectaspid arthropod from the Early Cambrian Sirius Passet Fauna, with a description of retrodeformation based on functional morphology. Palaeontology 42: 99-122. 
Burrows M. 2007. Kinematics of jumping in leafhopper insects (Hemiptera, Auchenorrhyncha, Cicadellidae). The Journal of Experimental Biology 210: 3579-3589.

Burrows M, Picker MD. 2010. Jumping mechanisms and performance of pygmy mole crickets (Orthoptera, Tridactylidae). The Journal of Experimental Biology 213: 23862398.

Carew TJ. 2000. Behavioral Neurobiology - The Cellular Organization of Natural Behavior. Sunderland: Sinauer Associates Incorporated.

Diaz GA. 1998. Description of the last seven pelagic larval stages of Squilla sp. (Crustacea, Stomatopoda). Bulletin of Marine Science 62: 753-762.

Feist R, Lerosey-Aubril R, Johnson R. 2010. Coaptative devices, enrollment, and life habits in Paralejurus, a particular case in scutelluid trilobites. Palaeobiodiversity and Palaeoenvironments 90: 125-137.

Field LH, Glasgow S. 2001. 16. Defence Behaviour. Pp. 297-316 in: Field LH, ed., The Biology of Wetas, King Crickets and their Allies. Oxon, New York: CABI Publishing.

Fisher DC. 1977. Functional significance of spines in the Pennsylvanian horseshoe crab Euproops danae. Paleobiology 3: 175-195.

Giesbrecht W. 1910. Stomatopoden. Erster Theil. Fauna und Flora des Golfes von Neapel und der angrenzenden Meeresabschnitte 33: 1-239.

Golovatch SI. 2003. A review of the volvatory Polydesmida, with special reference to the patterns of volvation (Diplopoda). African Invertebrates 44: 39-60.

Greenwood JG, Williams BG. 1984. Larval and early post-larval stages in the abbreviated development of Heterosquilla tricarinata (Claus, 1871) (Crustacea, Stomatopoda). Journal of Plankton Research 6: 615-635.

Gurney R. 1942. Larvae of Decapod Crustacea. London: Adlard and Son.

Haug C, Haug JT, Waloszek D, Maas A, Frattigiani R, Liebau S. 2009. New methods to document fossils from lithographic limestones of southern Germany and Lebanon. Palaeontologia Electronica 12: 6T, 12p.

Haug JT, Maas A, Waloszek D. 2010. †Henningsmoenicaris scutula, $\uparrow$ Sandtorpia vestrogothiensis gen. et sp. nov. and heterochronic events in early crustacean evolution. Earth and Environmental Science Transactions of the Royal Society of Edinburgh 100: 311-350.

Haug C, Mayer G, Kutschera V, Waloszek D, Maas A, Haug JT. 2011. Imaging and documenting gammarideans. International Journal of Zoology: 380829. doi:10.1155/2011/380829

Haug C, Van Roy P, Leipner A, Funch P, Rudkin DM, Schöllmann L, Haug JT. 2012a. A holomorph approach to xiphosuran evolution - a case study on the ontogeny of Euproops. Development Genes and Evolution 222: 253-268.

Haug JT, Briggs DEG, Haug C. 2012b. Morphology and function in the Cambrian Burgess Shale megacheiran arthropod Leanchoilia superlata and the application of a descriptive matrix. BMC Evolutionary Biology 12: 162.

Haug JT, Waloszek D, Maas A, Liu Y, Haug C. 2012c. Functional morphology, ontogeny and evolution of mantis shrimp-like predators in the Cambrian. Palaeontology 55: 369-399.
Haug JT, Caron J-B, Haug C. 2013. Demecology in the Cambrian: synchronized molting in arthropods from the Burgess Shale. BMC Biology 11: 64.

Manning RB, Provenzano Jr AJ. 1963. Studies on development of stomatopod Crustacea I. Early larval stages of Gonodactylus oerstedii Hansen. Bulletin of Marine Science of the Gulf and Carribean 13: 467-487.

Mayer G, Haug JT, Maas A, Waloszek D. 2013. Functional aspects of the gammaridean mandibles with special reference to the lacinia mobilis (Crustacea, Amphipoda). Zoologischer Anzeiger 252: 536-547.

Morgan SG, Goy JW. 1987. Reproduction and larval development of the mantis shrimp Gonodactylus bredini (Crustacea: Stomatopoda) maintained in the laboratory. Journal of Crustacean Biology 7: 595-618.

Müller KJ, Walossek D. 1987. Morphology, ontogeny, and life habit of Agnostus pisiformis from the Upper Cambrian of Sweden. Fossils and Strata 19: 1-124.

Poinar G Jr. 2010. Palaeoecological perspectives in Dominican amber. Annales de la Société Entomologique de France 46: 23-52.

Provenzano Jr AJ, Manning RB. 1978. Studies on development of stomatopod Crustacea II. The later larval stages of Gonodactylus oerstedii Hansen reared in the laboratory. Bulletin of Marine Science 28: 297-315.

Racheboeuf PR, Vannier J, Anderson LI. 2002. A new threedimensionally preserved xiphosuran chelicerate from the Montceau-les-Mines lagerstätte (Carboniferous, France). Palaeontology 45: 125-147.

Schmidt J. 1926. Further studies of sun-fishes made during the Dana expedition, 1921-1922. Nature 117: 80-81.

Schmidt J. 1931. Oceanographical Expedition of the Dana, 1928-1930. Nature 127: 444-446, 487-489.

Shanbhogue SL. 1975. Descriptions of stomatopod larvae from the Arabian Sea with a list of stomatopod larvae and adults from the Indian Ocean, and a key for their identification. Part 1. Journal of the Marine Biological Association of India 17: 196-237.

Stein M, Selden PA. 2012. A restudy of the Burgess Shale (Cambrian) arthropod Emeraldella brocki and reassessment of its affinities. Journal of Systematic Palaeontology 10: 361-383.

Swaffar SM, O’Brien WJ. 1996. Spines of Daphnia lumholtzi create feeding difficulties for juvenile bluegill sunfish (Lepomis macrochirus). Journal of Plankton Research 18: 1055-1061.

Tang RWK, Yau C, Ng W-C. 2010. Identification of stomatopod larvae (Crustacea:Stomatopoda) from Hong Kong waters using DNA barcodes. Molecular Ecology Resources 10: 439-448.

Wedmann S, Bradler S, Rust J. 2007. The first fossil leaf insect: 47 million years of specialized cryptic morphology and behavior. Proceedings of the National Academy of Sciences 104: 565-569.

Received: 21 December 2013

Revised and accepted: 22 May 2014

Published online: 6 June 2014

Editor: R. Vonk 